\title{
The Construction of Student's Peer Psychological Field in Age of We-Media
}

\author{
Xue $\mathrm{Han}^{1}, \mathrm{Bo} \mathrm{Wu}^{2}$ \\ 1) Psychological Health Education Center, Nanjing Communications Institue of Technology, Nanjing, Jiangsu, China \\ 2) Department of Mathematics, Nanjing University of Finance and Economics, Nanjing, Jiangsu, China
}

Abstract - This paper mainly discusses the combinition of we-media and the work peer psychological health education in universities. use convenient, since the media quickly anddiffusion characteristics, we established the college students peer psychological field using the characteristics of we-medai with convenient and quickly anddiffusion. The study attend to expand the influence the work.

Keywords - Peer psychological field, We-media, College students

\section{自媒体时代大学生朋辈心理场域的构建}

\author{
韩雪 $^{1}$ 吴波 $^{2}$ \\ 1) 南京交通职业技术学院心理健康教育中心, 南京, 江苏, 中国 \\ 2) 南京财经大学应用数学学院, 南京, 江苏, 中国
}

\begin{abstract}
摘 要 高校朋辈心理健康教育工作在自媒体平台中的运用价值及其可行性分析。运用自媒体的便捷、迅速及扩散性等特点, 建 立大学生朋辈心理场域, 扩大高校朋辈心理健康教育工作的影响力度, 使高校心理健康三级网络织得更紧更密, 进而切实提高大学生 的心理健康水平。
\end{abstract}

关键词 朋辈心理场域, 自媒体, 大学生

1. 引言

随着互联网信息技术的快速发展, 自媒体以其私人化、 平民化、普泛化、自主化等传播特点, 广泛受到大学生的 青睐。在众多自媒体平台中, 微信是大学生乃至亚洲地区 最大用户群体的移动即时通讯软件, 其明星插件“朋友圈” 更是受到大学生的热捧。在朋友圈内, 成员之间以视频、 图文或单纯文字的形式或发表议论, 或分享经验。成员相 互之间对各自的观点进行评论和发表见解。这使得大学生 彼此之间的关系从线下发展延伸到线上，丰富了彼此间的 交往方式和内容。

然而, 大学时期正是一个人的世界观、人生观、价值 观形成的关键时期, 尽管大学生具有一定程度的认知能力, 能够进行自我观察、自我评价和自我完善[1], 但这些还不 足以从容应对多元经济、政治、文化激荡融合的信息化时 代对青年一代的挑战。现代社会的信任危机与网络监管的

江苏省高校哲学社会科学研究项目支持（资助号:2014SJD254）
滞后性并不能保证朋友圈里都是“好朋友”。在网络互动交 流的过程中, 处于网络集群中的大学生容易受群体行为和 情绪感染而变得无所顾忌、肆意言说, 严重时可引发大范 围的群体與论暴力和网络與情危机[2]。由此可见, 在自媒 体高速发展的时代, “朋友圈”中智慧的言论对大学生心理 成长起着举足轻重的作用。拥有智慧, 传递正能量的朋友, 我们称之为智友。

\section{2. 朋辈心理场域的定义}

\section{1 场域的概念}

场域理论是社会心理学的主要理论之一, 是关于人类 行为的一种概念模式, 它起源于 19 世纪中叶的物理学概念 [3]。场域是指一个人和他所处的环境中, 所有共同存在、 相互倚赖的因素。人的每一个行动均被行动所发生的场域 所影响, 场域中的所有现象都有潜在的同等关联, 人或环 
境的任何一部份小小的改变, 都会透过整体而显露。格式 塔治疗大师培尔斯强调“此时此地” (here and now) 是唯一 的心理实存(psychological real1ty)。他批评精神分析将潜意 识视为一个实体, 被压抑的感觉和经验驻扎此间的观念。 他并不否认每一件事物皆有其过去的来源, 并会朝向未来 进一步的发展, 但强调过去和未来皆持续不断从当下的场 域中开花结果, 也必须和当下联结[4]。

\section{2 朋辈心理场域的界定}

全朋辈心理咨询起源于 20 世纪六七十年代的美国, 20 世纪 80 年代逐渐转入我国台湾、香港地区, 21 世纪初, 我 国内地各高校开始对此项工作进行研究和实践。朋辈心理 咨询指由受过半专业训练并受督导的学生运用语言或非语 言的交流, 对需要帮助的朋辈提供倾听、支持或咨询的服 务[5]。研究表明, 大学生在遇到心理困扰时, 往往喜欢向 同龄人打开心扉, 更加愿意寻求朋辈的帮助[6]。因此, 在 高校心理咨询机构中, 设立朋辈心理工作站, 会辅助专业 心理咨询, 解决大学生发展性心理问题, 实践证明这是有 效的 [7]。

以“我们是朋友, 我们没有辈分”为工作宗旨, 朋辈心 理咨询员始终充当着在校大学生的智友角色。在朋辈心理 咨询中, 朋辈心理咨询师与来访者均为大学生, 均处于人 生成长过程中相似时期。随着咨访关系的深入, 咨询师与 来访者的角色界限也越来越模糊, 积极的咨访关系会促使 双方各自优秀的心理品质向对方传递, 消极的心理品质会 在关系中逐渐消退甚至瓦解, 双方在关系中相互存在、相 互依赖, 共同成长, 最终形成一个动态的积极心理能量平 衡空间。在进一步的咨询中, 双方会在这个空间中感受到 更多的共鸣, 进而使朋辈心理咨询师和来访者共同成长。 这个相互依存、相互感受、共同成长的积极的心理关系共 同构建成朋辈心理场域。

\section{3. 朋辈心理场域的定义}

在自媒体时代, 朋辈心理场域显然是积极而又有效的。 当代大学生对网络的认知已经非常熟悉和了解, 自媒体社 交平台已经成为大学生生活中不可分割的一部分。以微信 为例, 大学生会在朋友圈中宣泄和表达情绪, 寻求心理共 鸣; 会在朋友圈中树立自我形象, 拓宽社交渠道; 会在朋 友圈中评论时事, 表明政治立场。正是这种资源的共享性 使得朋友圈内形成了一个私密的组织, 不被陌生人打扰, 使得圈内的感情更加的牢固 [8]。在朋友圈内, 无论成员彼 此间是否为好友, 所有人在朋友圈内都会被别人的情感表 达潜移默化地影响着, 一个人微小的改变, 都会透过朋友
圈而显露、放大。微信, 已经成为当代大学生生活中重要 的心理场域。事实上, 人们更加倾向于接收含有积极情感 的信息, 即使性格内向的人, 也会在固定的人际交往中得 到积极的情感支持 [9]。在朋友圈中建立朋辈心理场域, 可 以人为而又不露痕迹地注入些健康积极的观念与情感, 以 互联网的扩散性, 这些会被迅速地传递到每个在校大学生。 朋辈心理场域可以使大学生心理健康教育更加高效、便捷、 迅速和贴近生活, 其具体建构包括以下几个步骤:

1、朋辈心理咨询员选拔。对自愿报名的大学生进行心 理健康、人格特质和人际关系等方面的心理测量, 剔除心 理不健康或人格不适合从事心理咨询的学生。然后, 按照 国家心理咨询师职业道德对测量合格学生进行面试。

2、朋辈心理咨询员培训。按照国家心理咨询师 (三级) 考试标准设置课程, 内容涵盖普通心理学、发展心理学、 社会心理学、变态心理学、咨询心理学 (包括个体咨询、 团体咨询、咨询伦理)、网络文明礼仪等内容。

3、朋辈心理咨询员考核。朋辈心理咨询员考核成绩采 用百分制, 由三个部分构成, 其中, 心理咨询基础理论知 识占 $30 \%$; 心理咨询技能占 $60 \%$; 咨询伦理与职业道德占 $10 \%$ 。成绩合格者准予聘用。

4、朋辈心理场域织网。分为线下织网和线上织网。前 者为高校普遍建立的心理健康三级网络工作体系。朋辈心 理场域处在第三级网络中。线上织网则要利用自媒体开展。 理想的线上朋辈心理场域是, 朋辈心理咨询员在微信朋友 圈中的好友范围要遍布所有在校大学生。但由于互联网的 扩散性, 即使朋辈心理咨询员的朋友圈没有广泛覆盖全校 范围, 但这不会影响朋辈心理场域的构建。

5、朋辈心理场域的控制与引导。

6、效果反馈机制。对大学生在朋辈心理场域中接受信 息情况进行反馈, 便于及时调整信息内容。

7、效果评估。运用访谈法、问卷法、实验法等研究方 法, 对朋辈心理场域的实施效果进行评估。

\section{4. 自媒体时代大学生朋辈心理场域的控制与引导}

朋辈心理场域的效果取决于对其控制和引导。科学家 研究认为, “人是惟一能接受暗示的动物。”[10]积极的暗示, 会对人的情绪和生理状态产生良好影响, 激发人的内在潜 能, 发挥人的超常水平, 使人进取, 催人奋进。而消极的 人会在不知不觉中偷走人们的梦想, 使人们渐渐颓废, 变 得平庸。朋辈心理场域要始终营造出积极的暗示, 必然需 要对自媒体话题的内容进行严格意义上的指导。这些话题 可分为以下几类。

1、积极与励志。定期编撰并刊登具有积极意义、阳光 心态、励志进取的图文, 让处于朋辈心理场域的大学生拥 
有智慧的正能量。

2、疗伤与治愈。运用心理咨询与治疗的理论、方法和 技术, 结合生动活泼的生活案例, 向朋辈心理场域内的大 学生传递正确的心理信息, 纠正错误的观念, 打破既定思 维, 达到疗伤与治愈的功效。

3、放松与分享。美妙的语言可以在人的大脑中建构一 幅幅生动的画面, 我们在杜甫的《春夜喜雨》中看到花团 锦簇的春天, 甚至能嗅到湿润空气中的悠悠青草的芳香; 在马致远的 《天净沙-秋思》中感受到作者浪迹天涯的肝肠 寸断。人们能够在阅读中能够在文字的基础上加工成图像、 声音, 进而传递到各个感觉器官, 仿佛有身临其境之感。 自媒体朋辈心理场域中, 适当频率的优秀心理文学小品配 以美图，会让场域中的个体体验到放松之感。

4、有争议的心理话题。自媒体朋辈心理场域出现的个 体间的理想信念、价值观念以及兴趣爱好呈现出多元特征。 研究发现, 人们在社会交往中, 个体接触到不同观点, 尤 其在与他人讨论问题的时候, 所遇到的不同意见会“迫使” 个体重新思考和定义自己再社会问题上的立场和态度[11]。 设立有争议的心理话题, 会使朋辈心理场域中的个体在讨 论中逐渐形成正确的或积极的心理观念。

此外, 我们还可以在朋辈心理场域中运用所开发的 APP 心理软件开展趣味心理测试和调查, 在与场域中的个 体互动过程中传递积极心理能量。

\section{5. 结语}

自媒体的高速发展给当今高校带来了便利, 同时也带 来了诸多挑战。如今越来越多的大学生宁愿在慕课上学习, 甚至自费到教育机构购买课程, 也不愿在教室中认真听讲。 高校课堂中经常能见到这样的画面: 教师在滔滔不绝地讲 课, 学生却在手机上奋笔疾书。一些高校开展诸如“无手机 课堂”等学风建设活动, 但效果并不显著。与其堵截, 不如 充分开发高科技给高校教学管理带来的潜在契机。借助自 媒体平台, 在高校中创建朋辈心理场域, 能够拓宽朋辈心 理咨询的工作范围, 使高校心理健康工作的三级网络织得 更密, 更紧。

\section{参考文献(References)}

[1] L. Han, "Psychological analysis of College Students' Network Forum," Journal of Guangzhou University (Socail Science Edition), vol. 35, no. 3, pp. 74-77, 2010.

[2] Z. Yuliang, "The reasons of accidents of network public opinion formation and guiding control strategy," Journal of Information, vol. 31, no. 4, pp. 54-57, 2012.

[3] W. Xiangzeng, "Network social networks overview," Field Theory Based on The World, vol. 76, no. 12, pp. 24-26, 2012.

[4] P. Joyce and C. Sills. Gestalt counselling and treatment technology. China Light Industry Press, 2005.

[5] M.B. Sussman, "The development and effects of a model for training peer group counselors in a multi-ethic junior high school," Dissertation Abstracts International, vol. 36, no. 4, pp. 626-631, 1973.

[6] X. Fugang and X. Jin, "Let peer tutoring implementation," Chinese Journal of Mental Health in University, vol. 18, no. 12, pp. 858-860, 2004.

[7] H. Xue, "Practice and research in higher vocational colleges peer workstation running mechanism," Taiyuan City Journal of Career Academy, vol. 22, no.10, pp. 266-268, 2014.

[8] W. Ruyan, "Study on the influence to Hohhot-3 of college students interpersonal WeChat college students as an example," Lanzhou University, 2014.

[9] T. Lumei and Z. Jianling, "The relationship between College Students' explicit self-esteem, implicit self-esteem, personality traits and positive emotion, negative emotion," China Mental Health Journal, vol. 55, no. 3, pp. 196-216, 2009.

[10] Z. Ruiqi, "Psychological hint of magic," The mass psychology, vol. 15, no. 5, pp. 21-22, 2004.

[11] L. Ye. "Use of media, media evaluation, social communication and Chinese social thought trend with three opinions," Journalistic University, vol. 28, no. 6, pp. 65-66, 2012. 